\title{
NHS dental service utilisation and social deprivation in older adults in North West England
}

DOI:

10.1038/sj.bdj.2017.624

\section{Document Version}

Accepted author manuscript

Link to publication record in Manchester Research Explorer

\section{Citation for published version (APA):}

Mckenzie, K., Pretty, I., \& Goodwin, M. (2017). NHS dental service utilisation and social deprivation in older adults in North West England. British Dental Journal, 223(2), 102-107. https://doi.org/10.1038/sj.bdj.2017.624

\section{Published in:}

British Dental Journal

\section{Citing this paper}

Please note that where the full-text provided on Manchester Research Explorer is the Author Accepted Manuscript or Proof version this may differ from the final Published version. If citing, it is advised that you check and use the publisher's definitive version.

\section{General rights}

Copyright and moral rights for the publications made accessible in the Research Explorer are retained by the authors and/or other copyright owners and it is a condition of accessing publications that users recognise and abide by the legal requirements associated with these rights.

\section{Takedown policy}

If you believe that this document breaches copyright please refer to the University of Manchester's Takedown Procedures [http://man.ac.uk/04Y6Bo] or contact uml.scholarlycommunications@manchester.ac.uk providing relevant details, so we can investigate your claim.

\section{OPEN ACCESS}




\title{
NHS dental service utilisation and social deprivation in older adults in North West England
}

\author{
K. W. McKenzie, ${ }^{* 1}$ M. Goodwin ${ }^{1}$ and I. Pretty ${ }^{1}$
}

In brief

Decribes the use of NHS dentistry in the older population.

Details the type of treatments provided to older adults and patterns with regards to their age and deprivation level.
Suggests a more preventive approach to managing older adults in a general dental care setting is required, reducing barriers to accessing care.

Objective To explore NHS dental service utilisation (attendance and treatment activity) of older adults. Design Retrospective analysis of dental treatment claim forms (FP17s) over a 15 month period. Population A total of 690,433 older adults in North West England. Results NHS dental care attendance decreased with increasing age; $49 \%$ in $65-74$ years, 39\% in $75-84$ years and $23 \%$ in the over 85 years age group. Across all older age stratifications, the more deprived patients had a higher rate of examinations, extractions, dentures and preventative advice compared to the least deprived patients. However, the relationship was opposite for the rate of fillings and complex restorative treatment; the rate was higher for the least deprived older adult patients. Conclusions Despite $95 \%$ of older adults living in the community, the number of older adults accessing NHS dental care in this data set is thought-provoking. Additionally, there is a complex relationship between the type of treatment provided and the patient's IMD level. The authors acknowledge the major limitations of this dataset; affluent people are more likely to access private dental care and the availability of NHS dental services is likely to vary across different regions. However, the use of 'big data' is necessary to provide a pragmatic approach for future research in the management of older adults in general dental services.

\section{Introduction}

The population aged over 65 is becoming a larger proportion of the UK's total population. The main driver for population ageing is improved mortality at all ages, but particularly at older ages, due to improved overall living conditions, nutrition, smoking habits and better health care and technological advances. ${ }^{1}$ Over the last 30 years the percentage of the population aged 65 and over increased from $15 \%$ in 1985 , to $17 \%$ in $2010^{2}$ and to $20.1 \%$ in mid-2015, ${ }^{3}$ with this $5 \%$ increase representing 2.6 million people in this age group. By 2035 it is predicted that $23 \%$ of the population will be over 65 , with the fastest population increase

'The University of Manchester, Dental Health Unit, Williams House, Manchester Science Park, Lloyd Street North, Manchester, Greater Manchester M15 6SE ${ }^{*}$ Correspondence to: Miss Kate Wise McKenzie Email: kate.mckenzie@manchester.ac.uk

Refereed Paper. Accepted 20 March 2017 DOI: 10.1038/sj.bdj.2017.XXX in those over 85-years-old, referred to as the 'oldest old'.,

This demographic change continues, but not uniformly, across all parts of the UK. In rural coastal areas there is a higher percentage of older adults with lower levels found in urbanised areas. ${ }^{5}$ Figure 1 uses raw figures from the two most recent censuses to depict this trend in older age groups in the North West of England, a geography that encompasses a wide range of regional differences.

Although the North West population is living longer, it continues to experience a lower life expectancy compared to the national average; 76.0 for males, 80.4 for females versus 77.7 and 87.8 years respectively. ${ }^{7}$ Although living longer should be commended and enjoyed, the health and well-being of the expanding older population is becoming an increasing challenge and priority to public services. ${ }^{8}$ Ageing is not necessarily synonymous with ill-health and dependency, but it cannot be ignored that as people age they are more likely to live with complex comorbidities and disability. ${ }^{9,10}$ Based on 2009
National Indicators, $25.0 \%$ of over- $65 \mathrm{~s}$ in the North West rated themselves 'not in good health', significantly worse than the England's average of $21.5 \%{ }^{7,11}$ Despite this, most people over 65 live with a long-term condition and most people over 75 live with three or more. ${ }^{12,13}$

With the natural population growth being smaller than previous years due to falling fertility rates,${ }^{14}$ there is an increasing proportion of older people requiring a greater amount of health care service with relatively fewer working-age people (aged 16-64 for men, 16-59 for women) to support them. ${ }^{5}$ There has been a shift in health care provision by commissioners to focus towards prevention and long-term care ${ }^{15}$ and this has also been recognised in dentistry. ${ }^{16}$ However, unlike younger cohorts, evidence-based management of older adults is limited in a general dental practice setting.

The ageing dentition presents its own complexities and those individuals with natural teeth can often present with pain and infection, whereas their edentulous peers are often free 
of oral pain or discomfort. Dental and public health professionals have been successful in improving the oral health of the population, so much so that the prevalence of edentulousness is now $6 \%$ vs. $28 \%$ nearly 40 years ago. ${ }^{17}$ With the improving levels of dental disease in the younger population, it is predicted that older adults will make up a larger proportion of the dental patient-base in the UK. ${ }^{18,19}$ Dental care providers are now faced with a preventative paradox; there are more older patients, with more teeth, with a wider range of clinical issues complicated by risks association with long-term conditions and effects of poly-pharmacy. ${ }^{20}$

It is also important to recognise the impact of setting as uptake of NHS dental care and access becomes increasingly problematic with increasing age, ${ }^{20}$ especially the frail elderly. ${ }^{21}$ Previous work on older adults has mainly concentrated on those living in institutionalised care, a readily accessible population for research. However, fewer than $5 \%$ of all older adults live in such settings ${ }^{22,23}$ and the burden of disease is experienced by communitydwelling elders, often living independently or cared for by relatives. ${ }^{20}$

The rationale for this research is as follows:

- Dental caries (root and coronal) is still the leading cause of tooth loss in older adults and studies have confirmed that older adults are a caries-active population, similar to that of younger age groups ${ }^{24-26}$ with around one new carious lesion per year

- With increasing natural tooth retention there is a need for a more strategically preventative long-term approach to combat the difficulties, faced by both the practitioner and patient, in the management of the failing dentition, ${ }^{27}$ in particular of the 'heavy metal generation'28

- A potential burden to dental services is developing due to a combination of an ageing population, increased risk of dental disease and limited evidence-based guidelines - all of which are further complicated by increased patient expectations ${ }^{29}$

- Predicting the future for oral health in the ageing population has been well described,,$^{20,27}$ however, to plan NHS dental services for this cohort, it is prudent to consider the potentially varying needs of the distinct age groups that form the ageing population

- Since there is a well-established link between poor oral health and socioeconomic deprivation ${ }^{30}$ more information is needed on the impact of these dental health

Fig. 1 Proportion of the older population in North West of England using figures from 2010 census compared to 2015 census $^{6}$

12

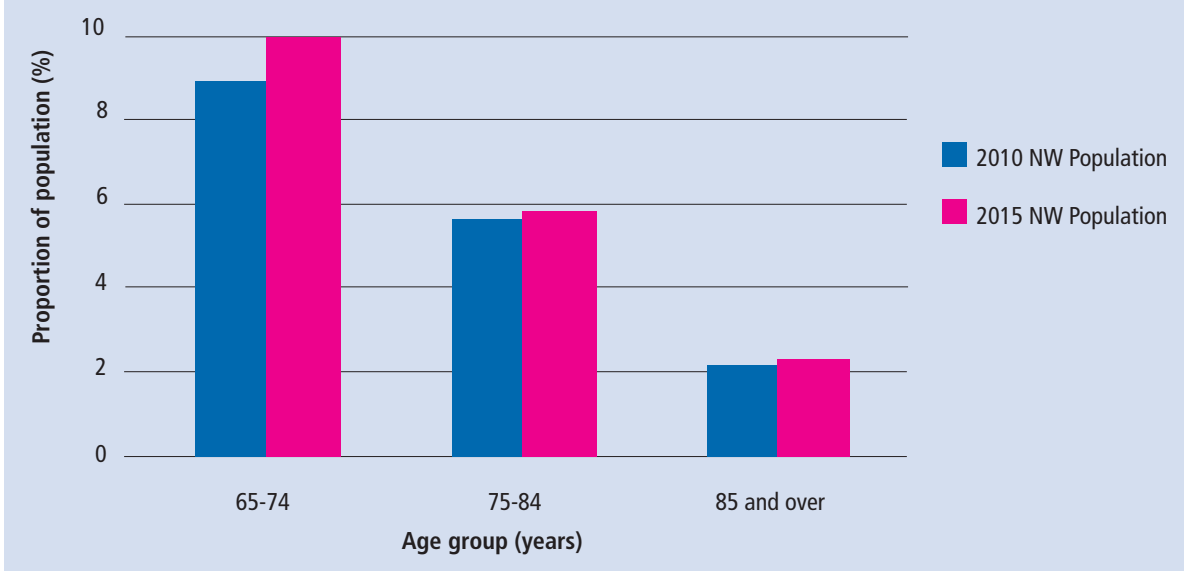

inequalities in older adults. Traditional measures of deprivation, for example based on postcode, may not apply to older adults who may live in affluent areas but are on low incomes due to loss of earning and reliance on pension schemes.

This paper will be used to inform future research study regarding population ageing in dentistry, identifying and understanding both the risk factors related to this public health issue and to explore preventative strategies that could prepare NHS primary dental care services and their practitioners to be more 'age-friendly'.

\section{Aims}

1. To develop an understanding of NHS dental service utilisation (demand and treatment activity) in older adults in North West of England

2. To determine patterns of dental treatment undertaken in older adults across the socio-economic levels and age ranges from NHS dental practices in the North West of England.

\section{Method}

Data from NHS dental practices in North West of England (Greater Manchester, Lancashire and Merseyside) was imported to Microsoft Excel from the NHS Business Service Authority (BSA). The dataset provides the number of treatment claim forms (FP17s) submitted by general dental practitioners in a 15 -month period, April 2014 to June 2015. The number of FP17s were analysed in relation to patient's age and the level of deprivation, measured by the Index of Multiple Deprivation (IMD). IMD ranks areas in England from most to least deprived (1 to 10) based on seven different domains and split into equal groups, allowing for comparisons between deciles. ${ }^{31}$

Dental service demand was measured by the attendance for NHS dental care. This was calculated as a proportion of those who attended a NHS dentist from the NHS BSA data over the total population in the same geographical area from the most recent census. ${ }^{3}$ Demand met by the independent sector is not accounted for by this BSA dataset. Dental treatment activity (type of treatment and frequency) was analysed by the 'rate', which is a straight calculation per $100 \mathrm{FP} 17 \mathrm{~s}$, that is, how often a certain treatment appears on all courses of treatment.

Since the NHS BSA data uses raw figures, the reporting was limited to descriptive statistics. Older adults in this paper were considered as those over 65 years of age and divided into older age bands: 65-74, 76-84 and 85 and over. For dental service demand the next younger age group, 55-64 years, were also incorporated for comparative context.

\section{Results}

There were 690,433 older adults in the NHS BSA data set and their age groups were stratified into: $65-74,75-84$ and 85 years and older. Table 1 shows the dental attendance rates for each older age group (including the 55-64 age group) in the 15-month period, from April 2014 to June 2015. 
Table 1 Proportion of the older population in North West of England accessing dental care

\begin{tabular}{l|l} 
Age group, years & Dental attendance rate \\
\hline $55-64$ & $51 \%$ \\
\hline $65-74$ & $49 \%$ \\
\hline $75-84$ & $39 \%$ \\
\hline 85 and over & $23 \%$ \\
\hline
\end{tabular}

The results show that the dental service demand in the NHS decreases with increasing age; in the 55-64 years age group the dental care attendance was $51 \%$ compared to $23 \%$ in the 85 years and over age group.

When analysing the raw numbers, there were more treatment claim forms (FP17s) submitted for the most deprived patients compared to the least deprived across all age stratifications as shown in Table 2.

The dataset provided more detail into the different types of treatment provided across the deprivation levels for each older age group. The extraction rate and upper acrylic denture rate for older adults are shown in Figure 2.

It is evident that the rate of both treatments, per $100 \mathrm{FP} 17 \mathrm{~s}$, decreased the lower the IMD decile level for each older age group. The overall average difference in the rate of extractions was 1.5 times greater in the highest decile compared to the lowest decile. For the rate of acrylic dentures the overall difference was 3.4 times greater. The highest number of upper acrylic dentures were given to the most deprived adults aged 85 and over, at a rate of 11.9 per $100 \mathrm{FP} 17 \mathrm{~s}$. Data regarding fluoride varnish application also follows a similar

Table 2 Total number of treatment claim forms submitted (FP17s) across each older age group in North West of England

\begin{tabular}{l|l|l|l} 
IMD Decile Rank & \multicolumn{2}{l}{ Total FP17s } & 85 and over \\
\cline { 2 - 4 } & $65-74$ & $75-84$ & 5,533 \\
\hline 1 (most deprived) & 65,400 & 28,723 & 4,125 \\
\hline 2 & 44,246 & 19,143 & 4,219 \\
\hline 3 & 41,246 & 19,003 & 3,620 \\
\hline 4 & 41,392 & 18,657 & 3,977 \\
\hline 5 & 41,005 & 19,202 & 4,267 \\
\hline 6 & 41,620 & 20,043 & 4,442 \\
\hline 7 & 49,845 & 23,030 & 4,498 \\
\hline 8 & 48,129 & 22,521 & 4,785 \\
\hline 9 & 46,526 & 22,781 & 3,172 \\
\hline 10 (least deprived) & 27,624 & 14,507 &
\end{tabular}

pattern for all older age groups albeit it within small denominations. The rate of fluoride varnish for the most deprived decile was 2.7 , 2.8 and 2.9 per $100 \mathrm{FP} 17 \mathrm{~s}$ for $65-74$ years, 75-84 years and 85 and over, respectively, compared to 1.9, 1.8 and 2.3 for those in the least deprived decile.

However for more complex restorative treatments, such as permanent fillings, endodontics, crown and bridgework, the rate was higher in those least deprived compared to most deprived. Figure 3 depicts the rate of permanent fillings per $100 \mathrm{FP} 17$ between the older age groups.

There is a gradual overall increase in rate of fillings with a decrease in IMD level. The largest disparity between the social deprivation levels and treatment rate can be seen in adults aged 85 and over: a fillings rate of 19.8 for the most deprived and 28.1 for the least deprived, 1.4 times higher. The relationship between other restorative work and IMD levels in older age groups are not as obvious due to their low frequency on FP17s and therefore have not been included schematically.

Data regarding preventive advice provided to older adults within this data set is presented in Figure 4 as a bar chart.

The rate of best practice prevention was at the lowest in the most and least deprived older adults, while following an undulating pattern in between. This relationship was observed in each older age group. Overall, the average rate of best practice prevention for older adults was 44.3 per $100 \mathrm{FP} 17 \mathrm{~s}$ submitted in the 15 -month time frame investigated.

Fig. 2 The rate per 100 FP17s of extractions and upper acrylic dentures in the older population

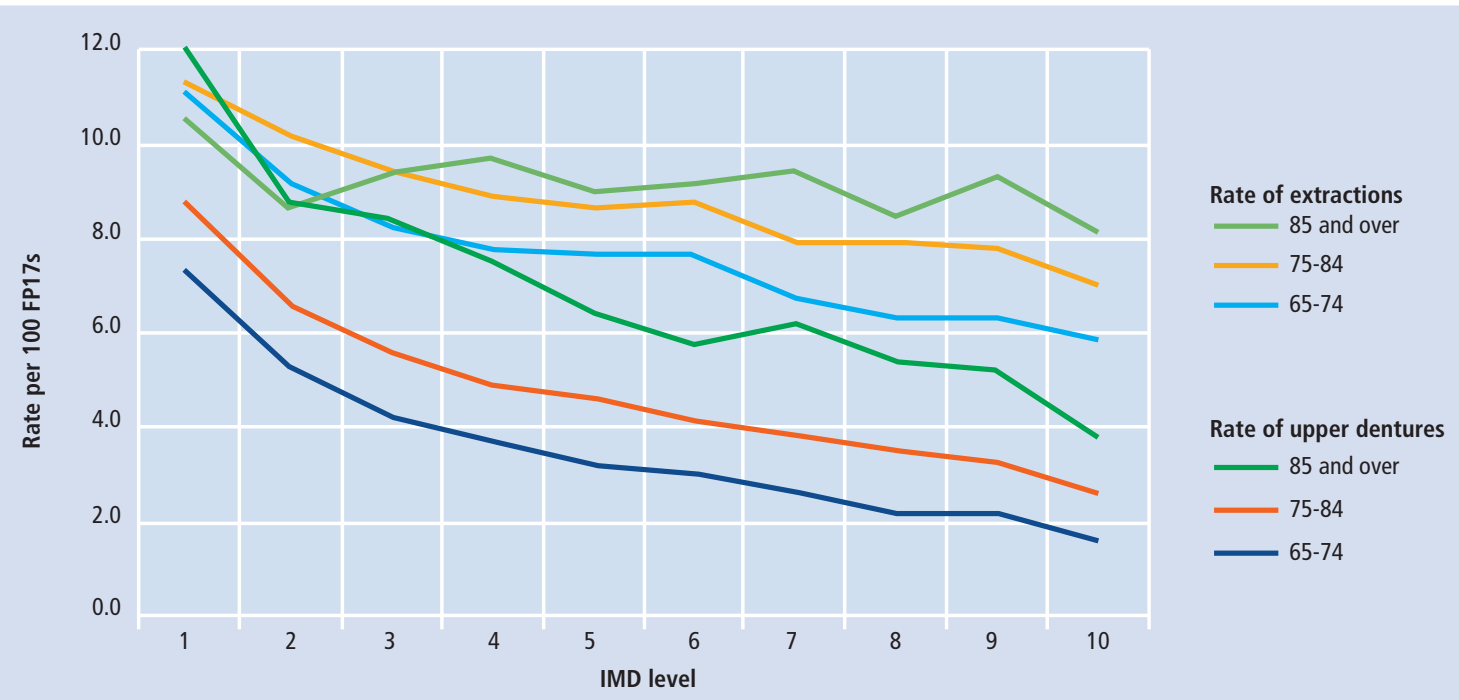


Fig. 3 The rate per $100 \mathrm{FP17s}$ of permanent fillings in the older age groups

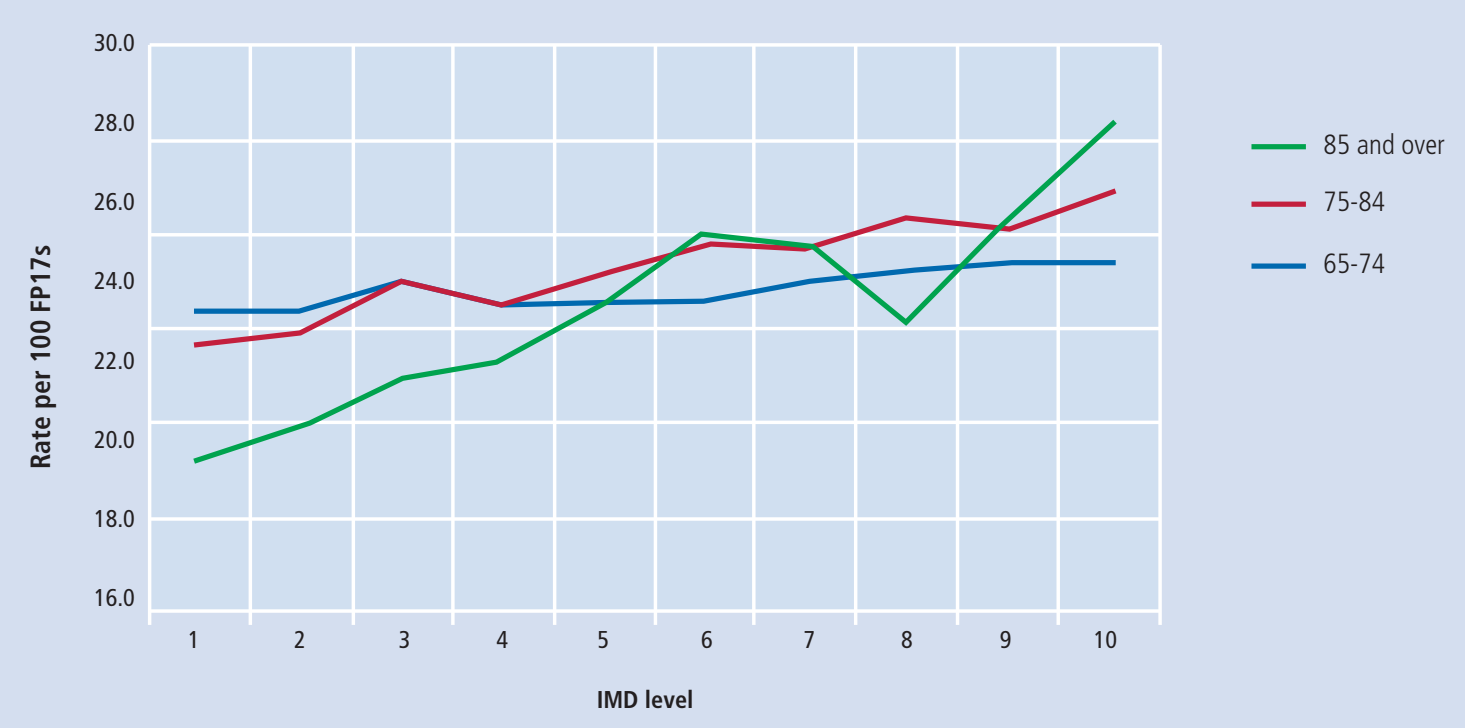

\section{Discussion}

The results showed a complex relationship between older age, deprivation and dental service demand. Table 1 shows the NHS dental service demand in the North West of England reduced with increasing older age. The authors acknowledge many of the limitations in the application of this data. Firstly, the denominator used for the percentage dental attendance rate (the overall older adult North West population) was derived from population estimates from the Office for National Statistics' census ${ }^{3}$ and the cross boundary flow between the individuals and their dental practice is likely to limit the accuracy of this calculation. Secondly, the decreasing dental attendance pattern cannot be extrapolated to the UK as a whole given how access and availability of NHS services is likely to vary from region to region. Thirdly, the NHS BSA dataset does not account for the use of dental services outside of the NHS. It must be acknowledged that more affluent people are likely to access dental care privately. Currently older people do not automatically receive free NHS dental treatment by virtue of age, only if they are on defined benefits. The Adult Dental Health Survey has limited this information by geography rather than older age groups so it would be useful to determine the proportion of older adults that qualify for free NHS dental care and the impact this has on them accessing it.

However, the dental attendance rate pattern is still thought provoking. With only $3.2 \%$ of over 65-year-olds in England residing in care homes, ${ }^{32}$ why is there such a large proportion of community-dwelling older adults not accessing general NHS dental care? With a growing number of frail and functionally dependent older people living at home one could postulate that they are not being appropriately signposted or that oral care is not seen as a priority. These data may support a theory that such individuals are not in pain, or have no functional deficit however, earlier work suggests that around 50\% of older adults complain of oral discomfort. ${ }^{33}$ Even in surveys, such as one conducted in a North London community, ${ }^{34} 52 \%$ of frail older adults who participated in the study reported that they preferred to receive dental care in their own homes and complained of inadequate transportation options to dental providers. In such instances, an interdisciplinary and interprofessional framework is required to ensure continuum of care.

Unsurprisingly, Gilbert et al. ${ }^{11}$ found that older adults with natural teeth were more likely to seek dental care than edentulous elders and those with more teeth were associated with more dental visits. Additionally, the likelihood of seeking dental care increased four-fold if the older person was edentulous in one arch only or has at least one tooth in each arch, compared with those with no natural teeth. ${ }^{35}$ However, with edentulism becoming a less common dental characteristic over the last 20 years, as well as increasing patient expectation, the relatively low uptake of NHS dental care still needs to be explored. Work with older adults suggests that they highly value access to a dentist, and this did not diminish with age or carer status. The need to maintain food choices, being able to socialise and have dignity in appearance were all rated highly important by participants in a recent focus group. ${ }^{36}$ This asserted desire for access, when compared to the actual figures in Table 1, suggests that there is a barrier to care - rather than diminishing need.

Overall from this North West data, there is an interesting relationship between type of treatment provided to the older adult patients and their respective IMD level. The most deprived older adults showed an increased provision of NHS dental care with regards to routine examinations, prevention, extractions and upper acrylic dentures. However, for permanent fillings and more complex restorative treatment (endodontics, bridges, crowns, inlays and veneers) the relationship appeared to be an inverse one. The disparity between dental treatment types and IMD level cannot be answered. For example, the rate of fluoride varnish application increases with increasing age and is higher in those that are least deprived. For direct comparisons to be made the different rates of edentulism across ages needs to be explored and how these are likely to different by deprivation status. Additionally from a qualitative perspective, the attitudes of the dentist and the health seeking behaviours of the patients would need to be explored. Although this is a large dataset, this research is exploratory and provides an interesting insight into the dilemma relating to restore versus extract as treatment options for the older patient, for example restorability decreasing with age and also concepts such as the Shortened Dental Arch (SDA). ${ }^{37}$ 


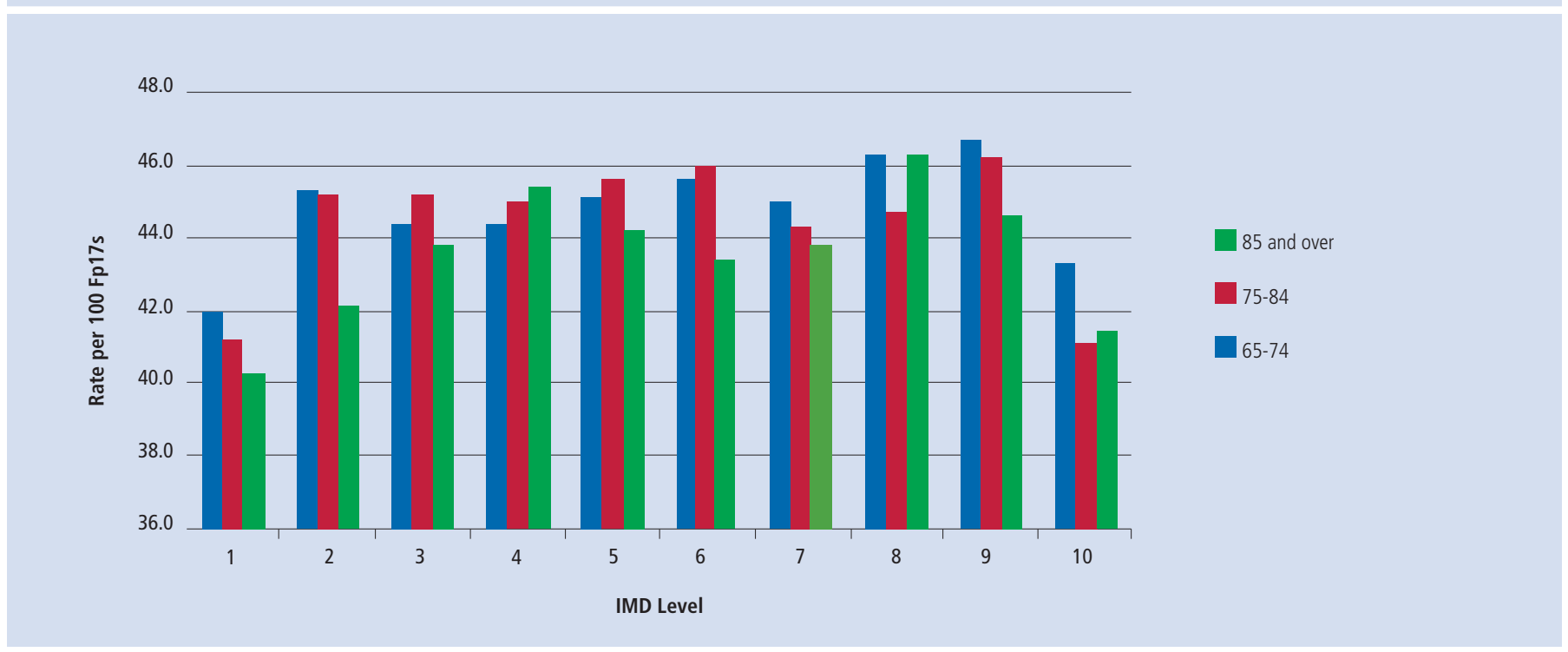

It is complex to compare the current data to earlier studies due to the focus on older adults in residential care and the limitation of the current work is that the reasons for the dental treatments cannot be assumed that is, due to caries, trauma or periodontal conditions (although the concept of 'healthy survivors' in periodontal disease may suggest that the majority of disease is caries ${ }^{40}$ ).

Furthermore, the accuracy by which the FP17s are correctly completed is unknown. For example, the best practice prevention is a box on the treatment claim form that should be ticked if the dentist has followed guidance as detailed in the evidence-based toolkit by the Department of Health's Delivering better oral health. ${ }^{16}$ However, this toolkit is largely composed of specific guidelines for children, with more general advice given for adults. Older adults, unlike children, are heterogeneous in nature and a 'one-size fits all' approach will not be effective in answering their dental health needs. Additionally, there are a multitude of caries risk assessment tools for the younger population which, due to the differences in risk factors, cannot be extrapolated to the older population. The complexities of research within this group need to be explored so that tailored advice can be given. This idea is harmonious with that of the British Dental Association who revisited their 'Oral Healthcare for Older People: 2020 Vision' policy paper in 2012. ${ }^{38}$

Arguably, the most important discussion point is the arbitrary nature of the age thresholds used in this paper as to what is considered to be 'old', 65 years and above. As a person ages, differing life trajectories drive a difference in health and wellbeing, ranging from genetic differences, to socioeconomic and behavioural factors. Categorising the older population in this way is rather onedimensional as it encompasses a wide range of people with varying needs. In medicine, the concept of frailty is influencing the way in which care to the older population is planned and provided. ${ }^{39}$ There is a plethora of frailty scales and geriatric assessments, of which the items within these reflect the major categories of impairments and barriers to 'health'. Pretty et al. have suggested a pathway in which this approach can be incorporated in dentistry to ensure effective prevention and treatment of the older adult population..$^{40}$

\section{Conclusions}

Despite the described limitations of the crosssectional data, they provide a picture of health service provision within this important population. As with all large data sets it is important to add detail and context so that the findings can be interpreted for policy makers and stakeholders. Further research will therefore be required to achieve this, by examining clinical records and decisions made by clinicians, with respect to older patients. This is needed to explore the individual characteristics of this cohort to determine the barriers and enablers of older adults' use of dental services and the best predictors of utilisation. Such work will cast further light on the complex interplay between age, deprivation, access and the treatments and preventive regimes offered to older adults in England.
1. Dunnell K. Ageing and mortality in the UK-national statistician's annual article on the population. Popul Trends 2008; 134: 6-23.

2. Office for National Statistics. Population Ageing in the United Kingdom, its Constituent Countries and the European Union. 2 March 2012. Available at: http:// webarchive.nationalarchives.gov.uk/20160105160709/ http:/www.ons.gov.uk/ons/dcp171776_258607.pdf (accessed June 2017).

3. Office for National Statistics. Population Estimates for UK, England and Wales, Scotland and Northern Ireland: mid-2015. Available at: https://www.ons.gov.uk/peoplepopulationandcommunity/populationandmigration/ populationestimates/bulletins/annualmidyearpopulationestimates/latest (accessed 27 February 2017).

4. Office for National Statistics. Ageing - Fastest increase in the 'oldest old'. 2009.

5. Bayliss J, Sly F. Ageing across the UK. Reg Trends 2010; 42: 2-28.

6. Office for National Statistics. Population Estimates for UK, England and Wales, Scotland and Northen Ireland: Mid-2010 Mid-2010 datasets. Available at: https:// cy.ons.gov.uk/peoplepopulationandcommunity/populationandmigration/populationestimates/datasets/ populationestimatesforukenglandandwalesscotlandandnorthernireland (accessed 5 July 2017).

7. Association of Public Health Observatories. North West. Heal Profiles 2010; 41: 133-133.

8. Department of Health. National Service Framework for Older People. London, 2002

9. Age UK. Access all ages. London, 2012.

10. Oliver D, Foot C, Humphries R. Making our health and care systems fit for an ageing population: King's Fund. Age Ageing 2014; 43: 731.

11. Public Health England. Older People's Health and Wellbeing. Public Heal. Profiles. 2016. Available at: https://fingertips.phe.org.uk/profile/older-people-health/ data\#page/0/gid/1938133103/pat/15/par/E92000001/ ati/6/are/E12000002/iid/90356/age/1/sex/4 (accessed 1 March 2017).

12. Barnett K, Mercer S W, Norbury M, Watt G, Wyke S, Guthrie B. Epidemiology of multimorbidity and implications for health care, research, and medical education: a cross-sectional study. Lancet 2012; 380: 37-43.

13. Banks J, Breeze E, Lessof C, Nazroo J. Living in the 21st century: older people in England: The 2006 English Longitudinal Study of Ageing, 2008.

14. Office for National Statistics. Births in England and Wales. 2016; 2011: 1-10.

15. Naylor C, Imison C, Addicott R, et al. Transforming our healthcare system. London: The King's Fund, 2015. Available at: www.kingsfund.org.uk/sites/files/kf/field/ field_publication_file/10PrioritiesFinal2.pdf (accessed 5 July 2017) 
16. Public Health England. Delivering better oral health: an evidence-based toolkit for prevention. London, 2014

17. Fuller E, Steele J, Watt W, Nuttall N. 1: Oral health and function - a report from the Adult Dental Health Survey 2009. The Health and Social Care Information Centre, 2011.

18. Kelly M, Steele J, Nuttall $\mathrm{N}$ et al. Adult dental health survey: oral health in the United Kingdom 1998. London, 2000.

19. Walls A W G, Steele J G. Geriatric oral health issues in the United Kingdom. Int Dent J 2001; 51: 183-187.

20. Public Health England. What is known about the oral health of older people in England and Wales. A review of oral health surveys of older people. London, 2015.

21. British Dental Association. Access to dental care for frail elderly people. 2015.

22. Tinker A, Anchor Trust. J, Hancock R, Mueller G, Stuchbury R. Eighty-five not out : a study of people aged 85 and over at home. Anchor Trust, 2001.

23. Aldridge $H$, Kenway $P$, Pannell J. Older people's housing: choice, quality of life, and under-occupation. York, 2012.

24. White D, Pitts N, Steele J, Sadler K, Chadwick B. 2 Disease and related disorders - a report from the Adult Dental Health Survey 2009. The Health and Social Care Information Centre, 2011.
25. Griffin S O, Griffin P M, Swann J L, Zlobin N. Estimating rates of new root caries in older adults. J Dent Res 2004; 83: 634-638.

26. Thomson W M. Dental caries experience in older people over time: what can the large cohort studies tell us? $\mathrm{Br}$ Dent J 2004; 196: 89-92.

27. British Dental Association. Oral Healthcare for Older People - 2020 Vision. 2003

28. Hellyer $\mathrm{PH}$. The older dental patient - who cares? $\mathrm{Br}$ Dent J 2011; 211: 109-111.

29. Borreani E, Jones K, Scambler S, Gallagher J E. Informing the debate on oral health care for older people: a qualitative study of older people's views on oral health and oral health care. Gerodontology 2010; 27: 11-18.

30. The British Dental Association. Oral Health Inequalities Policy. London, 2009.

31. Department for Communities and Local Government The English Index of Multiple Deprivation (IMD) 2015 - Guidance. 2015. https://www.gov.uk/government/ uploads/system/uploads/attachment_data/file/464430/ English_Index_of_Multiple_Deprivation_2015_-_Guidance.pdf (accessed 22 February 2016).

32. Office for National Statistics. Change in Older Resident Care Home Population between 2001 and 2011. 2014.
33. Pretty I A. The life course, care pathways and elements of vulnerability. A picture of health needs in a vulnerable population. Gerodontology 2014; 31 Suppl 1: 1-8.

34. Lester V, Ashley F P, Gibbons D E. Reported dental attendance and perceived barriers to care in frail and functionally dependent older adults. Br Dent J 1998; 184: 285-289.

35. Gilbert G H, Duncan R P, Crandall L A, Heft M W. Older Floridians' attitudes toward and use of dental care. J Aging Health 1994; 6: 89-110.

36. Brocklehurst P R, Mackay L, Goldthorpe J, Pretty I A. Older people and oral health: setting a patient-centred research agenda. Gerodontology 2015; 32: 222-228.

37. British Dental Association. Shortened dental arch therapy in old age BDA Evidence Summary. 2013

38. British Dental Association. Oral Healthcare for Older Peope - 2020 Vision Check-up January 2012. 2012

39. Oliver D. Ageing and Frailty: 'Game-changers' for our Health \& Care Services? MICRA Lecture. 11 May 2016 Available at: http://hummedia.manchester.ac.uk/institutes/micra/Events2016/Micra Lecture David Oliver Fina Edit.pdf (accessed 17 May 2016).

40. Pretty I A, Ellwood R P, Lo E C M et al. The Seattle Care Pathway for securing oral health in older patients. Gerodontology 2014; 31 Suppl 1: 77-87. 